\title{
A FORMAÇÃO INICIAL DO LICENCIANDO EM CIÊNCIAS BIOLÓGICAS E O TEMA SEXUALIDADE
}

\author{
THE INITIAL TRAINING OF LICENSING IN BIOLOGICAL SCIENCES AND \\ THE SEXUALITY THEME
}

\author{
LA FORMACIÓN INICIAL DEL LICENCIAMIENTO EN CIENCIAS \\ BIOLÓGICAS Y EL TEMA DE LA SEXUALIDAD
}

\author{
Eula Raissa Chaves de Almeida Corbagi ${ }^{1}$; Taitiâny Karita Bonzanini ${ }^{2}$
}

\begin{abstract}
Resumo
Práticas formativas devem relacionar-se com desafios vividos pelos profissionais cotidianamente, envolvendo domínio e construção de saberes exigidos na atividade docente. Portanto, este artigo objetivou discutir a formação do licenciando em Ciências Biológicas no tema sexualidade. Para tanto, foram submetidas à análise documental ementas de disciplinas obrigatórias e entrevistas semiestruturadas aplicadas aos discentes em 2016, ano que também foi concluída a pesquisa. Observou-se justificativa para abordagem do tema em 17 disciplinas, contudo, o curso pouco contribui à formação de professores aptos a trabalhá-lo na educação básica apesar de conter momentos propícios ao seu aprofundamento. Sugere-se que as licenciaturas passem a olhar favoravelmente à abordagem da sexualidade na formação docente, podendo considerar debates promovidos pelo movimento estudantil, salvo adequação metodológica, para desenvolver saberes necessários ao exercício da profissão docente.
\end{abstract}

Palavras-chave: Formação inicial de professores; Educação em sexualidade; Licenciatura em ciências biológicas; Ensino de Biologia.

\begin{abstract}
Training practices must relate to challenges experienced by professionals on a daily basis, involving mastery and construction of knowledge required for teaching. Therefore, this article aimed to discuss the formation of the graduate student in Biological Sciences on the topic of sexuality. To this end, they underwent documentary analysis, menus of mandatory subjects and semi-structured interviews applied to students in 2016, the year in which the research was also concluded. There was justification for addressing the topic in 17 subjects, however the course does little to train teachers to be able to work with it in basic education despite having moments to its deepening. It is suggested that undergraduate courses start to look favorably on the approach to sexuality in teacher's education, and may consider activities promoted by the students movement, except for methodological adequacy, to develop the necessary knowledge for the exercise of the teaching profession.
\end{abstract}

Keywords: Initial teacher training; Sexuality education; Degree in biological sciences; Biology Teaching.

\footnotetext{
${ }^{1}$ Mestranda em Ecologia Aplicada - Escola Superior de Agricultura "Luiz de Queiroz" - Universidade de São Paulo (ESALQ/USP). Professora - Rede de Cursinhos Populares Podemos +, PODEMOS +, Brasil. E-mail: eula.almeida@alumni.usp.br

${ }^{2}$ Doutora em Ensino de Ciências - Universidade Estadual Paulista (UNESP). Professora doutora - Universidade de São Paulo (ESALQ/USP) (USP). E-mail: taitiany@usp.br
} 


\section{Resumen}

Prácticas formativas deben relacionarse con retos experimentados por educadores cotidianamente, implicando dominio y construcción de conocimientos necesarios a la docencia. En este contexto, el presente artículo tuvo como objetivo discutir la formación en Ciencias Biológicas acerca del tema sexualidad. Para ello, fue realizada análisis documental de planes de estudios de asignaturas obligatorias y entrevista semiestructurada a estudiantes en 2016, año en el que también concluyó la investigación. Se justifica abordar la temática en 17 asignaturas, pero el curso poco contribuye para formar docentes capaces de trabajar esta temática en la educación básica, ambiente favorable para su profundización. Se sugiere que cursos de grado miren favorablemente al enfoque de la sexualidad en la formación docente, considerando actividades del movimiento estudiantil, con alguna adecuación metodológica, para desarrollar conocimientos necesarios a la docencia.

Palabras clave: Formación docente inicial; Educación sobre sexualidad; Licenciatura en ciências biológica; Enseñanza de la Biología.

$$
\text { *** }
$$

\section{Introdução}

Sexualidade é um conceito complexo de se definir, no entanto, há muito, estudiosos vêm discutido conceitos básicos referentes ao tema. A UNESCO, em 2019, revisitou documentos antigos sobre o tema, reuniu e apresentou uma definição operacional e uma matriz conceitual elaboradas por especialistas e aceitas de maneira consensual, trata-se das Orientações Técnicas Internacionais de Educação em Sexualidade.

Assim, a sexualidade pode ser entendida como uma dimensão central do ser humano que inclui: compreensão e relacionamento com o corpo humano, vínculo emocional, amor, sexo, gênero, identidade de gênero, orientação sexual, intimidade sexual, prazer e reprodução. A sexualidade é complexa e inclui dimensões biológicas, sociais, psicológicas, espirituais, religiosas, políticas, legais, históricas, éticas e culturais que evoluem ao longo da vida. (UNESCO, 2019, p. 17).

A partir da definição acima, a UNESCO reitera que "o processo de ensino e aprendizagem visando a Educação em Sexualidade baseia-se em aspectos cognitivos, emocionais, físicos e sociais da sexualidade", portanto, objetiva transmitir conhecimentos, habilidades, atitudes e valores ao educando de forma a fornecer-lhe "autonomia para: garantir a própria saúde, bem-estar e dignidade; desenvolver relacionamentos sociais e sexuais de respeito; considerar como suas escolhas afetam o bem-estar próprio e o de outras pessoas; entender e garantir a proteção de seus direitos ao longo de toda a vida." (UNESCO, 2019, p. $16)$. 
DOI: http://doi.org/10.46667/renbio.v14i1.526

Neste sentido, a Educação em Sexualidade em questão, carrega consigo características tais como: ser cientificamente fundamentada, gradativa, apropriada para a idade e para o estágio de desenvolvimento do educando, baseada em um currículo, fundamentada nos direitos humanos, transformadora, integral, alicerçada em igualdade de gênero, capaz de desenvolver as habilidades para a vida, necessárias para apoiar escolhas saudáveis, culturalmente relevante e adequada ao contexto. Portanto, as discussões neste presente artigo compreenderão designações conceituais anteriores, tais como o termo 'Orientação Sexual' - trazida pelos Parâmetros Curriculares Nacionais (PCN) de 1997 - ou o amplamente utilizado, 'Educação Sexual', dentre outros, como integrados, reformulados e acolhidos dentro da atual conceituação proposta pela UNESCO.

Sem mais delongas e dada a importância do assunto, esperar-se-ia que o tema compusesse o currículo da educação básica e fosse trabalhado de forma integralizada e interdisciplinar como de fato houveram movimentações e debates para tal, entretanto, após décadas de discussões e avanços sobre a temática, em 2017 "tudo relacionado à Gênero, Sexualidade e Educação Sexual foi retirado da Base Nacional Comum Curricular (BNCC), um recuo histórico e um retrocesso em relação aos PCN" (MONTEIRO \& RIBEIRO, 2020, p.10).

Nesse sentido, considerando que a realização da pesquisa incluída neste artigo foi finalizada em 2016, em um período de debates e transições da BNCC, buscou-se refletir sobre o preparo do professor de ciências e/ou biologia para a promoção da educação em sexualidade, visto que, tais temas e seus correlatos comumente lhes são atribuídos quando lecionam estas disciplinas (BORDINI, 2012), a sua formação inicial contribui para o desenvolvimento de discussões nesse sentido em sala de aula?

De acordo com Mello (2000), a formação inicial tem o papel de prover bases para a construção de pensamento pedagógico especializado, reconhecendo que ela é apenas um item de uma estratégia ampla de profissionalização de professores, é indispensável que se considerea essencial para efetivar políticas de melhoria da educação básica. No que diz respeito ao tema sexualidade, por exemplo, se na formação inicial o licenciando não teve a oportunidade de discuti-lo, isso pode refletir em ausência da construção dos saberes para abordá-lo no exercício de sua profissão. Assim, entende-se que as práticas formativas precisam estar relacionadas com os desafios que serão vividos pelos futuros docentes em seus cotidianos, trabalhando os saberes que serão exigidos para o exercício da profissão (GARCÍA, 1999; VEIGA \& AMARAL, 2002).

Pimenta (2002) reitera que o professor precisa utilizar os saberes pedagógicos, mobilizados a partir das dificuldades postas pela prática docente, ou seja, para saber ensinar não basta a experiência e os conhecimentos científicos, mas se fazem necessários os saberes pedagógicos e didáticos. Gauthier (1998), por sua vez, explica que muitos saberes foram criados sem levar em conta o professor real, na sua prática, mas sendo idealizados, o que chamou de Saberes sem Ofício, ou seja, os conhecimentos produzidos apenas na academia. Para ele, é 
DOI: http://doi.org/10.46667/renbio.v14i1.526

preciso propor um Ofício feito de Saberes, pois admite-se a existência de um repertório de conhecimentos próprios do ensino. Portanto, converter os idealizados Saberes sem Ofício em Ofícios feitos de Saberes é um caminho desafiador e mostra a necessidade de estudos e reflexões, erigindo assim, práticas acertadas para a sala de aula.

Tardif (2002), por fim, evidencia em seus estudos o pluralismo do saber profissional, relacionando-o com os lugares nos quais os docentes atuam, as instituições que os formam, aquelas onde exercem a profissão, seus instrumentos de trabalho e sua experiência. A prática docente, inserida na realidade existencial, deve levantar diversas demandas de discussão a respeito do tema sexualidade, pois está imerso no cotidiano, cultura, política e natureza. Seja na vivência individual ou esfera social e política, constantemente nos deparamos com questões relacionadas ao tema.

Portanto, observando interesses políticos que se traduzem em valores cotidianos na vida de cada cidadão, assuntos que permeiam a sexualidade no dia a dia precisam ser reconhecidos e discutidos nas salas de aula, pois a qualidade do ensino pode ser comprometida quando opressões e o senso comum sobrepõem o rigor científico e o fazer docente. Duas históricas distorções da vivência plena e saudável da sexualidade são, por exemplo, o machismo e homofobia, que comprometem a inclusão educacional e a qualidade do ensino, afastando o estudante oprimido e levando-o até mesmo à evasão (BRASIL, 1997).

Um exemplo prático dos motivos para discutir sexualidade na escola relaciona-se a questões sanitárias, econômicas e políticas, que impõem a necessidade de analisar a taxa de natalidade, a idade do casamento, a precocidade e a frequência das relações sexuais, aumento de infecções sexualmente transmissíveis (IST), gravidez não planejada, casos de abusos sexuais em menores de idade, dentre outros. Nesse contexto, o espaço escolar passa a existir como uma poderosa instância de reprodução das lógicas hegemônicas opressoras. Ali, a homofobia e o machismo são consentidos e ensinados, produzindo efeitos devastadores na formação de todos (BRASIL, 1997).

Sendo assim, será abordado ao longo do texto, a importância e o papel da formação inicial de professores de Ciências e/ou Biologia no que diz respeito à abordagem do tema sexualidade sob a compreensão dos conceitos inerentes ao termo Educação em Sexualidade. Para tanto, este tema, em seu amplo significado, será discutido com estudantes de Licenciatura em Ciências Biológicas, a partir de diferentes abordagens. Como a formação inicial preza pelo desenvolvimento de diferentes tipos de saberes, seja qual for o enfoque do assunto, ela precisa garantir que o futuro professor tenha condições de abordá-lo na educação básica contribuindo para a redução de mitos, vulnerabilidades e opressões relacionados ao tema, independentemente de suas crenças e valores pessoais. 
DOI: http://doi.org/10.46667/renbio.v14i1.526

Logo, o presente artigo objetiva discutir a formação do licenciando em Ciências Biológicas, para o trabalho com sexualidade na educação básica, a partir da análise do conteúdo programático das disciplinas do curso, descritos em suas ementas e, também, de respostas dos estudantes do referido curso a um questionário. Como sugestão para o trabalho com o tema, nesse artigo também se discute as contribuições de atividades realizadas pelo Movimento Estudantil (ME) para a formação de licenciandos comprometidos com a Educação em Sexualidade, como uma proposta formativa complementar.

\section{Procedimentos metodológicos}

As discussões desse artigo focalizaram o curso de Licenciatura em Ciências Biológicas da Universidade de São Paulo (USP), campus ESALQ, a partir da análise das ementas das disciplinas e das respostas dos licenciandos a um questionário.

O curso foi criado em 2002 e, de acordo com seu Projeto Político Pedagógico ${ }^{3}$ (PPP), "visa o desenvolvimento de profissional comprometido com valores democráticos e que compreenda o papel da escola e educação na sociedade atual", busca, então, "contemplar a formação integral do licenciando, ampliando seu capital cultural e aprofundando conhecimentos sobre aqueles a serem educados" por eles, em diversos contextos: sobre a sala de aula, a diversidade existente e as diferentes formas de educar e sobre os conhecimentos pedagógicos elaborados de acordo "com as áreas de conhecimento que serão objeto de ensino, valorizando a experiência e a reflexão sobre ela" (USP, 2015, p.03, grifo nosso).

Enquanto objetivo fundamental das Licenciaturas, conforme Programa de Formação de Professores ${ }^{4}$ da referida instituição, descreve-se a formação de professores como sujeitos de transformação da realidade brasileira, comprometidos com a busca de respostas aos desafios e problemas existentes em nossas escolas, especialmente naquelas da rede pública. Este mesmo documento afirma que os estudantes são auxiliados, pouco a pouco, a aprofundarem-se na compreensão da realidade educativa e dos pressupostos teórico-metodológicos presentes nas diferentes disciplinas que dão início a problematização desta realidade, procurando vias de ação efetivas pautadas pela realidade socioeducativa e diversidade dos estudantes e da escola, para o que cooperam os estágios propostos no início da segunda metade do curso.

\footnotetext{
${ }^{3}$ UNIVERSIDAdE DE SÃO PAULO. Escola Superior de Agricultura “Luiz de Queiroz". Projeto Político Pedagógico. Licenciatura em Ciências Biológicas. Publicação online disponível no link: https://www.esalq.usp.br/graduacao/sites/default/files/ppp biologia_licenciatura.pdf. p.10. 2015. Acesso em 29/04/2021

${ }^{4}$ UNIVERSIDADE DE SÃO PAULO. Pró-Reitoria de Graduação. Programa de formação de professoresUSP. Publicação online disponível no link: http://www4.fe.usp.br/wp-content/uploads/programa-de-formacaode-professores/programa-de-formacao-de-professores.pdf. p.38. 2004. Acesso em 29/04/2021
} 
DOI: http://doi.org/10.46667/renbio.v14i1.526

Considerando a importância de documentos que determinam conteúdos e temas trabalhados na formação inicial de professores, a primeira etapa da coleta de dados foi a análise documental, focalizando as ementas das 49 disciplinas obrigatórias para o curso de Licenciatura em Ciências Biológicas, disponíveis em plataforma pública e online, própria da Instituição. A análise objetivou verificar presença do tema sexualidade na grade curricular.

A análise documental constitui técnica importante na pesquisa qualitativa, seja agregando informações obtidas por técnicas outras, seja desvelando aspectos novos de um tema ou problema (LÜDKE; ANDRÉ, 1986). Consiste também, em identificar, verificar e apreciar os documentos com uma finalidade específica e, nesse caso, preconiza-se a utilização de fonte paralela e simultânea de informação para complementar os dados e permitir a contextualização das informações contidas nos documentos (MOREIRA, 2005). Para tanto, nessa pesquisa foram utilizados questionários,

Esse artigo valoriza o aspecto qualitativo de pesquisa e seu foco foi o cruzamento dos dados provenientes da análise documental das ementas com as concepções atribuídas por discentes em relação à sua formação inicial no que tange ao tema sexualidade, coletadas após uso de questionário. Para busca e análise das ementas, realizou-se seleção de termos chave definidos a partir de levantamento bibliográfico sobre formação de professores e o tema sexualidade, e em razão da abrangência de três grandes eixos:

a) O pedagógico: envolvendo a discussão, formação, instrumentalização teórica e/ou prática para abordar o tema no ensino básico, nas disciplinas de ciências e/ou biologia. Termos chave elencados: ensino de ciências, ensino de biologia, legislação do ensino, PCN e formação de professores;

b) O teórico-científico (ou biológico): associado às diversas formas de possível abordagem do tema durante o curso. Termos chave elencados: sexualidade, sexo, reprodução, comportamento e população;

c) O social: buscando relacionar a abordagem emancipatória no que diz respeito a quebra de tabus e opressões sistêmicas. Termos chave elencados: gênero, diversidade, diversidade sexual, diversidade de gênero.

A leitura na íntegra das ementas resultou na seleção de 17 disciplinas obrigatórias, distribuídas ao longo de 10 semestres de duração do curso. Os dados obtidos foram organizados em tabelas, evidenciando as informações das disciplinas selecionadas por semestre e discutidos qualitativamente com auxílio dos referenciais adotados no trabalho.

Considerando que as ementas das disciplinas poderiam não revelar exatamente o trabalho realizado em sala de aula, a coleta de dados a partir da análise documental foi complementada pela aplicação de questionário, com questões fechadas e abertas, junto a 
DOI: http://doi.org/10.46667/renbio.v14i1.526

graduandos finalistas. Um total de 16 questões foram elaboradas, sendo possível realizar uma análise fundamentada nos estudos de Lüdke e André (1986) sob a perspectiva da pesquisa em educação. Para elaborar o questionário, utilizou-se os Formulários (Forms) do Google, o qual atribuiu ao instrumento de pesquisa um alcance tecnológico que dialogasse com os sujeitos, bem como a praticidade de organização dos dados que a plataforma oferece.

Anteriormente à aplicação do questionário realizou-se um estudo piloto, ou seja, a aplicação de questionário pré-teste a um pequeno número de estudantes com o objetivo de validá-lo antes da aplicação final, observando aspectos funcionais, tais como pertinência, arranjo, perceptibilidade das questões, de modo a corrigir e/ou melhorar possíveis problemas, antes da aplicação definitiva (MARIUCI; FERRI; FELICETTI, 2012). O teste piloto caracteriza-se pelo estilo experimental e é aplicado a uma seleta amostra de participantes. Assim, a partir dele, foi possível realizar adaptações na redação de algumas questões (IRAOSSI, 2006), retirar e inserir outras.

O teste final foi aplicado a uma amostra de 21 estudantes. Anualmente ingressam 30 estudantes no referido curso e, o total de matrículas contemplando estudantes do $1^{\circ}$ ao $10^{\circ}$ semestre é cerca de 150, desconsiderando desistências ou ausência por intercâmbio. Selecionou-se estudantes que estivessem em seu $9^{\circ}$ semestre para aplicação dos questionários, por serem finalistas ainda presentes no cotidiano da instituição.

Foi requisitado na seção de graduação da unidade uma lista especificando quais e quantos eram os estudantes do $9^{\circ}$ semestre do curso para, então, realizar o contato com os sujeitos da pesquisa. Bem como, realizou-se uma busca ativa entre estudantes matriculados nas disciplinas do referido semestre. Para contatá-los utilizou-se a internet a partir do envio de convite por correio eletrônico para participar da pesquisa, seguido do Termo de Consentimento Livre e Esclarecido. Dos contatados, 10 participaram e responderam ao questionário online. Para preservar a identidade dos entrevistados, atribuiu-se nomes fictícios nas citações das respostas provenientes dos questionários. As respostas obtidas foram utilizadas para cruzamento com os dados obtidos a partir das ementas. 


\section{Resultados e discussões}

A discussão se iniciará pela apresentação das disciplinas nas quais pôde-se encontrar um ou mais termos chave durante a análise das ementas. Em ordem cronológica de acordo com seu período ideal dentro do curso. Na Tabela 1 constam-se as disciplinas obrigatórias do $1^{\circ}$ semestre, selecionadas a partir dos termos chave.

Tabela 1 - disciplinas selecionadas do $1^{\circ}$ semestre

\begin{tabular}{c|c|c|}
\hline Nome da disciplina & $\begin{array}{c}\text { Termo } \\
\text { chave }\end{array}$ & Justificativa da ementa \\
\hline Ecologia Geral & Populações & As populações e suas características. A comunidade. Interações dos \\
seres vivos na comunidade.
\end{tabular}

Fonte: dados da pesquisa.

Dentre as três disciplinas acima descritas, percebe-se que o possível debate sobre o tema sexualidade gira em torno do âmbito biológico/reprodutivo, seja a nível celular ou a nível populacional. No sentido de trazer à tona a problematização e resgate do termo sexualidade enquanto discussão interdisciplinar em busca de quebras de paradigmas na atual sociedade refletir-se-ia: 'como as espécies produzem gametas?' e ‘Como estabelecem-se predefinições no âmbito social a respeito da diferenciação da função social do indivíduo a partir do gameta que carregamos ao nascer?'

Além disso, é preciso discutir como o curso de formação em questão tem contribuído para a construção de saberes docentes pois, de acordo com Tardif (2002), o pluralismo do saber profissional está relacionado com os lugares nos quais os professores atuam, com as instituições que os formam, com as instituições onde trabalham, com seus instrumentos e sua experiência no trabalho. Ora, o professor de profissão não é somente alguém que aplica conhecimentos produzidos por outros, não é somente um agente determinado por mecanismos sociais: é um ator no sentido forte do termo, isto é, um sujeito que assume sua prática a partir dos significados que ele mesmo lhe dá, deixando de ser brinquedo inconsciente no jogo das forças sociais que determinam o seu agir.

Em Ecologia Geral, para além da caracterização das diferentes populações, observou-se espaço para a discussão sobre como se dão as relações intraespecíficas em espécies não humanas. Buscar compreender a fundo o possível limite entre instinto e cultura e, a partir desta compreensão, avançar no combate às opressões e violências gerados e estruturados em nossa 
DOI: http://doi.org/10.46667/renbio.v14i1.526

cultura. Em Zoologia de Invertebrados I, observou-se espaço para a seguinte reflexão: 'Existe, dentre estes grupos de invertebrados, comportamentos distintos entre os sexos de forma que, irracionalmente, desempenhem funções diferentes às estabelecidas aos sexos na espécie humana?' A análise evolutiva das relações intra e interespecíficas dentre os diferentes grupos traria grande contribuição comparativa para a compreensão do tema sexualidade em seu aspecto biológico e social.Em Biologia Celular, o estudo de diferentes gametas em diferentes espécies possibilita espaço para que aconteça a problematização quanto a atribuição de gêneros aos gametas. Bem como, o surgimento da vida e seu aspecto exímio em relação à atribuição de 'trejeitos' e papéis socialmente estabelecidas pela humanidade. A Tabela 2 indica as disciplinas obrigatórias do $2^{\circ}$ semestre.

Tabela 2 - disciplinas selecionadas do $2^{\circ}$ semestre

\begin{tabular}{c|c|c|}
\hline Nome da disciplina & Termo chave & Justificativa da ementa \\
\hline Zoologia de Invertebrados II & Reprodução & Aparelho reprodutivo. Reprodução e desenvolvimento \\
\hline Fonte: dados da pesquisa. & &
\end{tabular}

Nesta disciplina, o debate sobre o tema sexualidade gira em torno do âmbito reprodutivo de invertebrados a partir do filo Arthropoda, o que leva à análise e sugestões semelhante às referidas à disciplina Zoologia de Invertebrados I, no semestre anterior. Considera-se pertinente discussões sobre conceitos relacionados a anatomia e/ou fisiologia, pois o saber científico se faz necessário para o domínio da discussão do tema sexualidade e, segundo Pimenta (2002), é preciso informar e trabalhar com as informações para se construir a inteligência. E, de acordo com García (1999), o conhecimento que os professores possuem do conteúdo a ensinar também influencia o que e como ensinam. Contudo é preciso incentivar, durante as disciplinas, outras discussões relacionadas a saberes interdisciplinares.

No $3^{\circ}$ semestre não se localizou termos chaves nas ementas. Adiante, na Tabela 3 , observamos as disciplinas selecionadas do $4^{\circ}$ semestre. 
DOI: http://doi.org/10.46667/renbio.v14i1.526

Tabela 3 - disciplinas selecionadas do $4^{\circ}$ semestre

\begin{tabular}{|c|c|c|}
\hline Nome da disciplina & Termo chave & Justificativa da ementa \\
\hline Zoologia de Vertebrados I & $\begin{array}{l}\text { Comportamento, } \\
\text { Diversidade }\end{array}$ & $\begin{array}{l}\text { Caracterizar os cordados basais com base em sua } \\
\text { morfologia e biologia (história natural, comportamento, } \\
\text { fisiologia e ecologia) }\end{array}$ \\
\hline Bioestatística & População & Comparação de duas populações \\
\hline $\begin{array}{l}\text { Introdução aos Estudos da } \\
\text { Educação }\end{array}$ & $\mathrm{PCN}$ & $\begin{array}{l}\text { Escola de qualidade para todos, que valorize a cidadania, } \\
\text { a inclusão das camadas populares e os conhecimentos } \\
\text { básicos necessários à vida em sociedade, ao trabalho e a } \\
\text { manutenção de valores e ideais democráticos. Os } \\
\text { Parâmetros Curriculares Nacionais. }\end{array}$ \\
\hline $\begin{array}{c}\text { Evolução e Ecologia de } \\
\text { Populações }\end{array}$ & População & $\begin{array}{l}\text { Visa dar ao aluno um enfoque funcional das interações } \\
\text { existentes entre os organismos no nível de população e a } \\
\text { totalidade dos fatores físicos, biológicos e evolutivos que } \\
\text { afetam e são afetados por esses organismos. }\end{array}$ \\
\hline
\end{tabular}

Fonte: dados da pesquisa.

Nota-se que aqui aparece a primeira disciplina pedagógica na grade do curso e, justamente em sua ementa, observa-se a proposta de estudo dos PCN. Nesse documento existiam as indicações dos temas transversais, a saber: Orientação Sexual, Ética, Pluralidade Cultural, Saúde e outros. Apresenta, portanto, a indicação de temas relacionado à abordagem da sexualidade na educação básica de maneira interdisciplinar. Entende-se assim, que ao citar o estudo dos PCNs, dentre os diversos tópicos presentes na ementa desta disciplina, é possível que ocorram discussões que contribuam para que o futuro professor reflita sobre o tema orientação sexual contido de forma implícita nessa ementa, embora ainda assim, não seja garantida a sua abordagem e/ou enfoque.No geral, é importante destacar que as disciplinas que propõem introduzir um curso muito abrangente têm um enorme desafio: elencar os temas principais a serem abordados e organizá-los em uma ementa a partir de um cronograma de aulas que contemple a carga horária adequada. Ora, vale refletir o papel da disciplina de Introdução onde, exigir a abordagem de determinado tema em específico em detrimentos de outros, assemelha-se a um jogo político no qual decisões devem ser tomadas para que se cumpra com o objetivo de introduzir diversas áreas do curso aos estudantes no prazo de um semestre. Decisões estas caberiam à instituição, às comissões, sobretudo ao docente responsável pela disciplina e, sobre esse último, cabe refletir se durante sua formação e profissão também teve chances de participar de discussões a respeito do tema sexualidade para que, dessa forma, venha a sentir-se apto a colocá-lo em prática dentro da sala de aula.

Aponta-se, aqui, a necessidade de reflexão sobre professores responsáveis por suas respectivas disciplinas. Quando organizam suas aulas a partir de enfoque estritamente científico, é porque foi o único modo de formação que sempre vivenciou? Ora, de que maneira os formadores de futuros formadores pensam sobre seu fazer docente e como isso reflete sobre o aprendizado do licenciando? 
DOI: http://doi.org/10.46667/renbio.v14i1.526

A seguir, nas demais disciplinas elencadas, destacam-se a discussão sobre os estudos populacionais de cordados basais através de sua caracterização, ou seja, há uma possibilidade de reconhecer padrões comportamentais intraespecíficos que estudem a relação entre fêmea e macho e, também, sobre a reprodução da espécie, até mesmo estudar a possível existência de comportamentos homossexuais sob a ótica geral de diferentes populações e sob a ótica específica dentre as diversas espécies de vertebrados basais.

Cabe ressaltar que, quanto mais a fundo compreendemos a definição e o peso social da palavra gênero - até que ponto é cultural ou biológico, se já existiu tal atribuição em outras espécies, mais avançamos na compreensão, em humanos, de atribuições de papéis de gênero 'ser homem é vestir-se assim', 'ser mulher é fazer tais atividades', dentre outras questões. Pois, a partir da definição de sexualidade trazida neste artigo, entende-se se aplicar exclusivamente à espécie humana, porém, em um preparo ao futuro professor que lidará, em seu cotidiano, com diversos aspectos, nuances, origens e enraizamento das opressões que se estabelecem a cerca do tema dentro da sociedade, é recomendado desenvolver um olhar interdisciplinar e comparativo aos demais seres vivos e suas formas de existência.

Em outra perspectiva, ao estudar testes de hipóteses e questões estatísticas no geral, que muitas vezes utilizam como exemplos de exercícios e atividades conceitos carregados de padrões sexistas, tais como 'quantos homens jogam futebol' ou 'quantas mulheres lavam a louça' tidos como 'normais' na sociedade patriarcal que vivemos, o debate interdisciplinar sobre sexualidade poderia contribuir para que a utilização de exemplos a respeito da matéria lecionada seja mais inclusiva de forma a não reafirmar a cultura patriarcal. Por que não exemplificar 'quantas mulheres jogam futebol?', dentre outros exemplos mais inclusivos?

Adiante, seguindo para disciplinas obrigatórias elencadas no $5^{\circ}$ semestre, apresenta-se a tabela 4. Contudo, vale ressaltar que, a Comissão do Curso das Ciências Biológicas, em processo de reformulação da grade do curso, no ano de 2015, decidiu unificar duas disciplinas, a de Zoologia de Vertebrados I e II, para uma única disciplina chamada Cordados, o que pode contribuir para não haver ou não possibilitar tempo hábil para abordagem de diferentes enfoques do tema sexualidade e demais discussões pertinentes à formação docente. 
DOI: http://doi.org/10.46667/renbio.v14i1.526

Tabela 4 - disciplinas selecionadas do $5^{\circ}$ semestre

\begin{tabular}{|c|c|c|}
\hline $\begin{array}{c}\text { Nome da } \\
\text { disciplina }\end{array}$ & Termo chave & Justificativa da ementa \\
\hline $\begin{array}{c}\text { Zoologia de } \\
\text { Vertebrados II }\end{array}$ & $\begin{array}{c}\text { Comportamento } \\
\text { Diversidade }\end{array}$ & $\begin{array}{c}\text { Caracterizar os vertebrados endotérmicos (aves e mamíferos), } \\
\text { incluindo as formas extintas, com base em sua morfologia e } \\
\text { biologia (história natural, comportamento, fisiologia e } \\
\text { ecologia). }\end{array}$ \\
\hline $\begin{array}{c}\text { Estágio } \\
\text { Curricular em } \\
\text { Licenciatura }\end{array}$ & $\begin{array}{c}\text { Ensino de ciências, } \\
\text { ensino de biologia }\end{array}$ & $\begin{array}{c}\text { Ensino de ciências no ensino fundamental e biologia no ensino } \\
\text { médio }\end{array}$ \\
\hline
\end{tabular}

Fonte: dados da pesquisa.

Na disciplina de Zoologia de Vertebrados II, onde propunha-se o estudo aprofundado dos endodérmicos e, consequentemente, o estudo do modo de vida, comportamento e reprodução de espécies de mamíferos, eleva-se as possibilidades de discussão sobre sexualidade dentro do âmbito da existência, compreensão e atribuição de papéis de gênero em nossa cultura, contrapostos ao comportamento animal distinto entre fêmea e macho endodérmicos, no âmbito da diversidade sexual existente em espécies mamíferas, inclusive a humana.

Contudo, para aprofundar o debate na disciplina acima referida, com a intenção de contribuir com a formação de professores que não reproduzam pré-conceitos em seu fazer docente, faz-se necessário ampliar as discussões, ultrapassando-se a abordagem apenas biológica do conteúdo, incluindo o olhar pedagógico necessário à licenciatura.

Adiante, na Tabela 5, evidenciam-se as disciplinas seletas pertencentes ao $6^{\circ}$ semestre.

Tabela 5 - disciplinas selecionadas do $6^{\circ}$ semestre

\begin{tabular}{|c|c|c|}
\hline $\begin{array}{l}\text { Nome da } \\
\text { disciplina }\end{array}$ & $\begin{array}{l}\text { Termo } \\
\text { chave }\end{array}$ & Justificativa da ementa \\
\hline $\begin{array}{l}\text { Anatomia e } \\
\text { Fisiologia de } \\
\text { Vertebrados }\end{array}$ & Reprodução & $\begin{array}{l}\text { Sistema reprodutor masculino. Noções anatômicas: testículos, dutos, } \\
\text { pênis e órgãos acessórios. Espermatogênese e ejaculação. Sistema } \\
\text { reprodutor feminino. Noções anatômicas: ovários, útero, vagina e vulva. } \\
\text { Ciclo estral. Oogênese, fecundação, gestação, anexos embrionários e } \\
\text { parto. }\end{array}$ \\
\hline
\end{tabular}

Fonte: dados da pesquisa.

De acordo com a ementa, pode-se notar o total enfoque na discussão fisiológica/anatômica do tema sexualidade. Trata-se, contudo, do recorte ao grupo dos vertebrados que possui ampla diversidade de espécies, dentre as quais é possível discutir comparativamente a evolução dos sistemas e questões como instinto e prazer 
DOI: http://doi.org/10.46667/renbio.v14i1.526

Além dos conceitos científicos abordados, considera-se fundamental discussões sobre como ensinar tais conceitos na educação básica pois, concordando com Pimenta (2002), para saber ensinar não basta a experiência e os conhecimentos científicos, mas se fazem necessários os saberes pedagógicos e didáticos.

Entende-se que licenciandos, ao cursarem a disciplina de Anatomia e Fisiologia de Vertebrados, com a devida discussão sobre o tema sexualidade, poderiam ter maiores chances de consolidar o saber científico já relacionando-o com sua atividade profissional, refletindo sobre o saber pedagógico necessário para lecionar este tema ao ensino básico. Neste sentido, como nos diz Pimenta (2002), é preciso uma formação bem solidificada de maneira que o profissional tenha acesso ao conhecimento teórico e didático que necessita para uma prática pedagógica eficaz e diferenciada.

No $7^{\circ}$ semestre não foram localizadas disciplinas obrigatórias que apresentassem termos chave, portanto, na Tabela 6 , reuniu-se as disciplinas selecionadas do $8^{\circ}$ semestre.

Tabela 6 - disciplinas selecionadas do $8^{\circ}$ semestre

\begin{tabular}{|c|c|c|}
\hline $\begin{array}{l}\text { Nome da } \\
\text { disciplina }\end{array}$ & $\begin{array}{l}\text { Termo } \\
\text { chave }\end{array}$ & Justificativa da ementa \\
\hline $\begin{array}{l}\text { Política e } \\
\text { Organização da } \\
\text { Educação } \\
\text { Brasileira (POEB) }\end{array}$ & $\begin{array}{l}\text { Legislação } \\
\text { do Ensino }\end{array}$ & $\begin{array}{l}\text { Reconheça as etapas da constituição do sistema escolar brasileiro com } \\
\text { ênfase no estudo das principais legislações do ensino no Brasil, seu } \\
\text { contexto histórico, político e seus determinantes econômicos. }\end{array}$ \\
\hline $\begin{array}{l}\text { Atividades } \\
\text { Acadêmico- } \\
\text { Científico } \\
\text { Culturais (AACC) }\end{array}$ & $\begin{array}{l}\text { Legislação } \\
\text { educacional }\end{array}$ & $\begin{array}{l}\text { As atividades acadêmico-científico-culturais integram obrigatoriamente } \\
\text { os cursos de formação de professores e em conformidade com a } \\
\text { legislação educacional e, com o Programa de Formação de Professores, } \\
\text { constituem-se em requisito indispensável para a colação de grau do } \\
\text { licenciado. Tais atividades ampliam e aprofundam a formação sócio } \\
\text { cultural e científica do futuro professor }\end{array}$ \\
\hline $\begin{array}{l}\text { Qualidade de vida } \\
\text { e saúde }\end{array}$ & Populações & Epidemiologia, saúde pública e nível de qualidade de vida \\
\hline
\end{tabular}

As disciplinas selecionadas permitem aprofundar os estudos sobre as políticas educacionais do país, interdisciplinaridade sócio cultural e epidemiologia. Na disciplina POEB, caberia um espaço de discussão sobre quais foram os marcos e legislações que possibilitaram o avanço no combate ao machismo e à homofobia no sistema educacional brasileiro, por exemplo, possibilitando o trabalho do tema sexualidade em contexto social da formação docente, no entanto, pela análise da ementa não é possível inferir como ou se esse tipo de discussão ocorre. 
DOI: http://doi.org/10.46667/renbio.v14i1.526

Na disciplina, Qualidade de Vida e Saúde, a proposta de discussão gira em torno de propiciar o conhecimento básico sobre os conceitos de saúde pública e epidemiologia, mais especificamente sobre o conhecimento dos níveis de qualidade de vida e a distribuição de doenças - infecciosas ou não - seus condicionantes e consequências sociais e biológicas em populações humanas. Essa disciplina poderia constituir um espaço interessante para discussões sobre o tema sexualidade, desconstruir mitos sobre ISTs e debater seu caráter epidemiológico, entre outros

As disciplinas citadas anteriormente poderiam, também, contribuir para discussões sobre machismo, violência contra a mulher e homofobia nas escolas, que se manifestam tanto na dificuldade de reconhecimento e registro de assédios, acolhimento da vítima e direitos assegurados em caso de estupro ou, ainda, no reconhecimento de nome social, ainda que existam leis que assegurem tais direitos. Pode-se citar, ainda, temas que poderiam fomentar debates e discussões, por exemplo, a histórica restrição de indivíduos LGBT à doação de sangue devido a preconcepção de que estes são classificados como grupo de risco à transmissão de IST.

As disciplinas selecionadas do $9^{\circ}$ semestre estão representadas na Tabela 7.

Tabela 7 - disciplinas selecionadas do $9^{\circ}$ semestre

\begin{tabular}{c|c|c}
\hline Nome da disciplina & Termo chave & Justificativa da ementa \\
\hline $\begin{array}{c}\text { Metodologia do Ensino em } \\
\text { Ciências Biológicas I }\end{array}$ & $\begin{array}{c}\text { Ensino em ciências } \\
\text { biológicas e } \\
\text { ciências }\end{array}$ & $\begin{array}{c}\text { Prática de ensino supervisionada na escola. Análise, escolha e desenvolvimento } \\
\text { das metodologias de ensino em ciências biológicas e ciências e o preparo teórico } \\
\text { prático para a atividade como professor da escola básica, capaz de desenvolver- } \\
\text { se profissionalmente e buscar a autonomia profissional. }\end{array}$ \\
$\begin{array}{c}\text { Instrumentação para o } \\
\text { ensino de Ciências Biológicas }\end{array}$ & $\begin{array}{c}\text { Ensino de Ciências } \\
\text { Biológicas }\end{array}$ & Discussões sobre instrumentos para o trabalho com temas transversais \\
\hline
\end{tabular}

Fonte: dados da pesquisa.

Para a consolidação do saber docente, entende-se que os estágios obrigatórios possibilitam a construção de saberes sobre e na prática, pois o estudante deverá exercer atividades próprias do fazer docente, como a escolha dos conteúdos, metodologias de ensino e sua coerência com um projeto de emancipação, participação social e cidadania, tais como argumentam Pimenta (2002) e Tardif (2002), corroborando com o PPP do curso.

Nas disciplinas selecionadas, observa-se maior possibilidade de discussão em torno do ensino/aprendizado sobre sexualidade. Entretanto, apesar da indicação de estudos ou discussões sobre os temas transversais, elas não descrevem explicitamente quais dentre os temas serão abordados, tampouco, qual o enfoque. 
DOI: http://doi.org/10.46667/renbio.v14i1.526

Finalmente, na Tabela 8 evidencia-se a disciplina selecionada no $10^{\circ}$ semestre do curso, que passou a ser obrigatória no currículo a partir de sua ativação em 15/07/2015, para adequação ao Decreto n 5.626 de 22 de Dezembro de 2005 que regulamenta a Lei no 10.436, de 24 de abril de 2002, que dispõe sobre a Língua Brasileira de Sinais - Libras, e o art. 18 da Lei no 10.098 , de 19 de dezembro de 2000.

Tabela 8 - disciplinas selecionadas do $10^{\circ}$ semestre

\begin{tabular}{|c|c|c|}
\hline Nome da disciplina & Termo chave & Justificativa da ementa \\
\hline $\begin{array}{l}\text { Educação Especial e } \\
\text { Libras na Perspectiva } \\
\text { da Educação Inclusiva }\end{array}$ & $\begin{array}{l}\text { Ensino de } \\
\text { ciências. } \\
\text { Diversidade }\end{array}$ & $\begin{array}{l}\text { BLANCO, Rosa. A atenção à diversidade na sala de aula e as } \\
\text { adaptações do currículo. In: COLL, César; MARCHESI, } \\
\text { Alvaro; PALACIOS, Jesús (Org.). Desenvolvimento } \\
\text { psicológico e educação: transtornos de desenvolvimento e } \\
\text { necessidades educativas especiais. v. 3. Porto Alegre: Artmed. } \\
2004 \text {. } \\
\text { GAVILAN, Paloma. O trabalho cooperativo: uma alternativa } \\
\text { eficaz para atender à diversidade. In: ALCÚDIA, R. Atenção à } \\
\text { diversidade. Porto Alegre: Artmed, 2002. }\end{array}$ \\
\hline
\end{tabular}

Fonte: dados da pesquisa.

A leitura da ementa nos leva ao seguinte questionamento: Nesta disciplina discute-se o tema sexualidade dentro da perspectiva da inclusão de pessoas com deficiência? Ela aborda conceitos como: Educação Especial, Inclusão e Educação Inclusiva; Discussão dos marcos legais para a política de educação especial no Brasil; Tecnologia assistiva e a prática pedagógica no ensino de ciências, a educação de surdos no Brasil e a Língua Brasileira de Sinais. Logo, pode-se concluir que não se pode afirmar que o tema sexualidade será abordado.

De forma geral, é possível inferir que as ementas das disciplinas do curso de Licenciatura em Ciências Biológicas não indicam de forma explícita que o tema sexualidade é trabalhado a partir dos aspectos social e cultural. Mas, em algumas disciplinas, observa-se a indicação de que existe a abordagem teórico-científica (biológica) característica do estudo da vida e seu desenvolvimento.

\subsection{Análises das respostas dos estudantes}

Os dados coletados através dos questionários auxiliaram na reflexão sobre as diferentes interpretações trazidas sobre o tema sexualidade. Através das respostas pode-se relacionar o perfil em processo de formação e sua compreensão do tema nos diferentes enfoques. A maioria $(61,9 \%)$ dos licenciandos que participaram da pesquisa são do gênero feminino. Nesse sentido, ressalta-se a problematização dos papéis de gênero atribuídos em sociedade, que se refletem na predominância do gênero feminino em dadas profissões, por exemplo, na docência para o ensino básico. Assim como, a presença masculina se faz mais notável em cursos de ocupação pública, áreas de exatas e na política.

REnBio - Revista de Ensino de Biologia da SBEnBio - ISSN: 1982-1867 - vol. 14, n. 1, p. 12-31, 2021 
DOI: http://doi.org/10.46667/renbio.v14i1.526

Na sequência, com $100 \%$ dos entrevistados afirmando pretenderem obter o título de licenciado, notou-se uma falta de motivação em seguir a profissão docente, pois apenas 42,9\% deles responderam que pretendem lecionar. Tal desmotivação pode estar relacionada a vários fatores, dentre eles a desvalorização do professor no país, baixo salário, cortes de investimento na educação, ou mesmo a falta de esperança para seguir lutando por uma educação popular, gratuita e de qualidade. Logo, a pergunta que nos salta a mente é: se os futuros professores não lecionarão, então quem irá fazê-lo?

Em seguida, quando questionados sobre quais dos antigos temas transversais se sentiriam aptos a lecionar e quais não, obtiveram-se respostas incompletas, contudo, algumas delas elucidaram a consciência a cerca da formação inicial como papel fundamental para o futuro trabalho docente. A exemplo, temas que se sentiam preparados a lecionar: "Ética, meio ambiente, saúde e pluralidade cultural, sendo disciplinas que já fizeram parte da formação acadêmica." (resposta de D. Rocha). Também foram encontrados comentários que indicaram a evidente contribuição do $\mathrm{ME}$ local: "[...] não me sinto completamente preparada, mas possuo uma base de conteúdos de Ética, Orientação Sexual e Pluralidade Cultural oriundos principalmente da minha vivência com o movimento estudantil, em especial, a Entidade Nacional dos Estudantes de Biologia (ENEBio)” (resposta de S. Porto).

A análise das respostas nessa questão conduz a reflexão sobre o Saber sem Ofício, como apontado por Gauthier (1998), que se mostrou presente entre os finalistas do curso. Em contrapartida, a incerteza observada nas ementas, no que se refere a abordagem do tema sexualidade, indicam a necessidade de torná-lo um Ofício feito de Saberes, admitindo a existência de um repertório de conhecimentos próprios para o ensino do tema sexualidade, e que esse repertório precisa ser trabalhado durante a formação inicial.

Com relação aos temas que os estudantes não se sentiam preparados a lecionar, houve respostas que citavam majoritariamente o tema orientação sexual, tais como: “[...] Orientação sexual é polêmico pelo conservadorismo cultural brasileiro." (resposta de A. Ferraz). E justificativas como, 'não tive no currículo de licenciatura', 'não me sinto preparado' e 'falta de metodologias para tal' foram recorrentes, o que evidenciou a ausência ou insuficiente abordagem do tema sexualidade apesar das possibilidades observadas a partir das ementas.

Nas questões seguintes, buscou-se compreender o sentimento de preparo ou não do licenciando no âmbito de sua formação inicial para lecionar sobre sexualidade no ensino básico. Obtiveram-se comentários indicando que sequer existiu a abordagem do tema na graduação, outros categorizaram o tema como 'muito complexo' afirmando não ter aprendido muito bem como abordá-lo em uma sala de aula, enquanto alguns evidenciaram contato em espaços informais. "Acredito que o tema sexualidade não foi abordado de forma a se discutir o assunto na educação básica durante a graduação.” (resposta de G. Alves). 
DOI: http://doi.org/10.46667/renbio.v14i1.526

De acordo com Mello (2000), a educação escolar é uma política pública voltada à construção da cidadania. Ninguém facilita o desenvolvimento daquilo que não teve oportunidade de aprimorar em si mesmo. Ninguém promove a aprendizagem de conteúdos que não domina. Assim, quando um futuro professor declara, ao final de sua formação inicial, que não teve a oportunidade de estudar ou discutir determinado tema, logo nos questionamos sobre como poderá ensinar sobre um assunto ao qual não obteve preparo. Além disso, a formação inicial influencia diretamente nos saberes que se seleciona para trabalhar em sala de aula (TARDIF, 2002).

Acredita-se ser pouco provável que em nenhum momento o tema sexualidade tenha sido abordado em sala de aula ao longo do curso, pois a análise das ementas revelou que houve a abordagem biológica no decorrer dos semestres. Esses dados guiam a reflexão sobre os significados que os estudantes constroem sobre o tema e sua abordagem e se foram suficientes ou significativos para sua ampla compreensão.

Para compreender mais a fundo esses comentários, buscou-se resgatar na memória dos entrevistados as disciplinas que abordaram ou poderiam abordar o tema durante a graduação. Assim, 9,5\% sinalizaram contato com o tema em sala de aula, evidenciando que, em sua maioria não foi levado em consideração a abordagem biológica. Logo, é possível inferir que os estudantes responderam pensando no âmbito social do tema sexualidade, então, o dado evidencia a baixa recorrência da abordagem do tema neste aspecto. Frente à solicitação de justificativa, foram obtidos comentários como: "Fisiologia e anatomia animal, porém muito fraco pois era voltado para animais." (resposta de L. Cruz). Entende-se, portanto, que no geral a falta de interdisciplinaridade está presente nos conteúdos lecionados. Em seguida, 57,1\% de respostas positivas indicaram que o conceito de sexualidade é visualizado como sendo possível de ser abordado durante o curso.

A possível compreensão, por parte dos estudantes, sobre uma abordagem no âmbito mais social do tema sexualidade permanece implícita nas respostas obtidas. A respeito disso, quando foi questionado "qual(is) disciplina(s) você visualiza (possibilidade em abordar) e como deveria ser a abordagem do tema?", foram obtidas as seguintes repostas: "Introdução aos estudos em educação ao discutir os PCN. Comunicação e educação para entender formas de se comunicar sem discriminar minorias." (resposta de C. Gomez), e "Acredito que o estágio supervisionado poderia abordar o tema como proposta de estudo e elaboração sobre como ele é/ou poderia ser abordado em aulas do Ensino Básico.” (resposta de C. Silva).

A partir de então, iniciou-se a investigação a respeito de quais locais, além das disciplinas do currículo obrigatório, ter-se-iam tido contato com o tema. Observou-se que $52,4 \%$ apontaram que obtiveram contato com o tema em espaços não previstos na grade curricular. Evidenciando o importante papel de determinadas entidades e movimentos na construção de conhecimentos prévios típicos da vivência do futuro docente, por exemplo: 
DOI: http://doi.org/10.46667/renbio.v14i1.526

"Espaços do movimento estudantil, espaços de movimentos populares, rodas de conversa de amigos..." (resposta de B. Charles).

Nesse sentido, considera-se fundamental que os cursos de formação de professores abarquem as questões que se apresentam na prática diária do docente (Pimenta, 2002) evitandose o que não está relacionado às atividades do cotidiano escolar. Entretanto, o ME geralmente é formativo para o indivíduo que pretende ser docente, pois estimula e exercita atividades tais como planejamento, articulação, debate, viabilização de eventos, adequação, exposição, dentre outros exercícios. Salvo para um indivíduo que apenas observa, onde tal processo tenderá a ser menos formativo.

Por fim, encerrou-se o questioário com a seguinte pergunta: "Você considera o Movimento Estudantil da Biologia uma fonte de debates sobre o tema sexualidade? Justifique". Houve aqueles que nunca participaram ou que não compreendiam o ME, estes deixaram a questão em branco, responderam negativamente ou sem justificativa. Em contrapartida, algumas respostas diziam: "Sim. Dada a necessidade de discussão do tema sexualidade e a grande dificuldade de inclusão desse tema em outras disciplinas, já que nenhuma delas tem isso como um foco, o Movimento Estudantil é uma fonte muito importante de debates sobre o assunto.” (S. Porto). Tais respostas evidenciam a contribuição do ME para a formação de licenciandos comprometidos com o debate a respeito da sexualidade.

\section{Considerações finais}

A análise das ementas e as respostas aos questionários evidenciaram que o curso estudado pouco contribui à formação de professores para o trabalho com o tema sexualidade na educação básica, apesar de conter em sua grade momentos propícios para o aprofundamento da discussão de forma interdisciplinar. No entanto, somente a descrição presente na ementa não permite afirmar com certeza quais enfoques e como o tema é trabalhado em cada aula.

A visão dos licenciandos reafirma que a abordagem do tema no curso é insuficiente. Em contrapartida, pode-se indicar que atividades externas ao currículo como a realização de atividades temáticas do ME mostrou-se oportuna à complementação da formação de licenciandos, principalmente com relação a abordagem interdisciplinar do tema sexualidade, salvo adequação metodológica.

Considerando-se que a sexualidade é um assunto cotidianamente presente no exercer da profissão docente, sugere-se que os cursos de licenciatura passem a ter um olhar favorável à inserção do tema em seu currículo, pois a formação acadêmica é um momento estratégico na formação do profissional, sendo seu alicerce. 
DOI: http://doi.org/10.46667/renbio.v14i1.526

Finalmente, aponta-se a necessidade de pesquisas sobre a formação inicial e continuada dos docentes formadores de novos professores quanto ao tema, buscando responder algumas questões: Eles tiveram formação para tal? Como se deu essa formação e quais os desafios que eles encontram para replicá-la? Por fim, de que maneira eles pensam sobre seu fazer docente e como isso reflete no aprendizado do licenciando?

\section{Referências}

BORDINI, Santina Célia. O lugar da educação para a sexualidade na disciplina de ciências e suas relações com o saber científico. Contexto \& Educação. Ano 27, n. 88, p. 62-76, jul./dez. 2012.

BRASIL, Secretaria de Educação Fundamental. Parâmetros curriculares nacionais: pluralidade cultural, orientação sexual. Brasília, DF: MEC/SEF, 1997. 164p.

GARCÍA, Carlos Marcelo. Formação de professores: para uma mudança educativa. Portugal: Porto, 1999.

GAUTHIER, Clermont. Por uma teoria da pedagogia: pesquisas contemporâneas sobre o saber docente. Ijuí: INIJUI, 1998.

IRAOSSI, Giuseppe. The power of survey design: a user's guide for managing surveys, interpreting results, and influencing respondents. Washington, D.C.: The World Bank, 2006.

LÜDKE, Menga.; ANDRÉ, Marli Eliza Dalmazo Afonso. Pesquisa em educação: abordagens qualitativas. São Paulo: EPU, 1986.

MARIUCCI, Sergio Eduardo.; FERRI, Maricia Da Silva.; FELICETTI, Vera Lucia. Uma sombra na educação brasileira: do ensino regular ao paralelo. Revista Latino Americana de Educação Comparada, v. 3, p. 85-96, 2012.

MELLO, Guiomar Namo de. Formação inicial de professores para a educação básica: uma (re)visão radical. São Paulo Perspec. [online]. v. 14, n. 1, p. 98-110. 2000.

MOREIRA, Sonia Virgínia. Análise documental como método e como técnica. In: DUARTE, Jorge; BARROS, Antonio (Org.). Métodos e técnicas de pesquisa em comunicação. São Paulo: Atlas, p. 269-279, 2005.

PIMENTA, Selma Garrido (Org.). Saberes pedagógicos e atividade docente. 3. ed. São Paulo: Cortez, 2002.

MONTEIRO, Solange aparecida de Souza.; RIBEIRO, Paulo Rennes Marçal. Sexualidade e Gênero na atual BNCC: possibilidades e limites. Pesquisa e Ensino, v.1, p. 1-24, 2020.

TARDIF, Maurice. Saberes docentes e a formação profissional. Petrópolis: Vozes, 2002.

REnBio - Revista de Ensino de Biologia da SBEnBio - ISSN: 1982-1867 - vol. 14, n. 1, p. 12-31, 2021 
DOI: http://doi.org/10.46667/renbio.v14i1.526

UNESCO. Orientações Técnicas internacionais de educação em sexualidade: uma abordagem baseada em evidências. Disponível em:

https://unesdoc.unesco.org/ark:/48223/pf0000369308 . Acesso em: 17 de jan. 2021.

VEIGA, Ilma Passos Alencastro. Professor: tecnólogo do ensino ou agente social?. In:

VEIGA, Ilma Passos Alencastro; AMARAL, Ana Lúcia (Org.) Formação de professores:

políticas e debates. Campinas, SP: Papirus, 2002.

Revisão gramatical realizada por: Ellen Cristina Gonçalves Oliveira

E-mail: el.cgoliveira@gmail.com 